International Journal of Scholarly Papers for Media and Communjcations

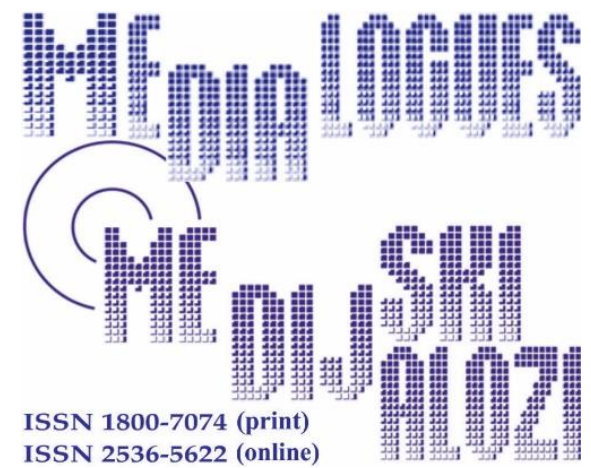

Mitrovic, B. (2016), „Information as a Product, Necessity and Prerogative in Digital Environment: the Case of Virtual Worlds", Media Dialogues / Medijski dijalozi, Vol. 14, No. 3, pp. 35-50.

\title{
Information as a Product, Necessity and Prerogative in Digital Environment: the Case of Virtual Worlds
}

BILJANA MITROVIC, PhD candidate

Faculty of Dramatic Arts, Belgrade, Serbia

\begin{tabular}{|c|c|}
\hline $\boldsymbol{A} \boldsymbol{R} \boldsymbol{T} \boldsymbol{I} \boldsymbol{C L} \boldsymbol{E}$ & $\begin{array}{r}\text { Received: February 17, 2021 / Revised from: MArch 18, 2021 } \\
\text { I N F } \boldsymbol{O}\end{array}$ \\
\hline DOI & Accepted: April 20 2021 / Available online: July 15, 2021 \\
\hline
\end{tabular}

\begin{abstract}
The aim of this paper is to examine the status of information in virtual worlds as well as information relating to these phenomena of the digi- tal environment, first and foremost bearing in mind MMORPG video games. The information to be analyzed include those required for using such types of digital environment - to play, or to dwell in virtual worlds as well as any material generated in them as a result of
\end{abstract}


activities in these environ- ments. Defined this way, information are viewed in relation to the concept of a game as a phenomenon of culture, then as an element of participatory culture, but above all as an important part of the economies of virtual worlds - the product or goods as result of labour, activities in the virtual world or a necessary prerequisite for playing or production in this environment. On the one hand, there is a need for the free flow and sharing of information characteristic for participatory culture, and on the other hand the capitalist model in relation to which the information is treated as a commodity created by the process of alienated labour.

KEYWORDS: Information, communications, virtual world, virtual economy, alienation.

\section{INTRODUCTION}

The use of computers and especially the Internet, has led to emergence of digital culture, which, as Charlie Gere notices, is also called cyberculture, electronic culture or the information age/society, all of which are associated with other similar terms such as information technologies (2008, pp. 17, 51-52). This designation shows a direct connection of the use of digital media (and virtual worlds as the most developed form in the field) and information systems, in the sense that the information is considered for the basic unit of digital environments.

As Gere (Ibid., p. 24) observes, "the operations of capitalism are fundamentally predicated on abstraction, standardization and mechanization"- precisely those phenomena that could have been offered by the machines that were working, keeping and trans- mitting information since their inception in the 19th century. The machines can offer what best suits the spirit of capitalism - the ability of different phenomena to be treated as equal and interchangeable (Ibid., p. 24). This exactly corresponds to the logic of "emphasis on the exchange value of commodities, rather than their use value" (Ibid., p. 24).

Analyzed this way, the emergence of information technology responds to the need for "evergreater amounts of information", which is in line with the capitalist pro- pensity "for more efficient and rational ways of producing profits" (Ibid., p. 29). In the late 20th and early 21 st century, with the increase of the importance and allencompassing use of computer systems, information technology, information systems and the information itself assumed a dominant role in many areas (Ibid., p. 30), so it can be concluded that they also posses great significance for capitalism itself (with the overproduction of information).

The subject of trade has become "information rather than actual products." (Ibid., p. 36), so the information is treated as a commodity. In this paper, the term "information" is understood in two ways: as "an information-supplying system that retrieves information, documents and virtual objects" (Buckland, 1991 in Harviainen 
and Hamari, 2015, p. 1121) and as such, it has to do with information technology and technical characteristics of digital media, platforms and programs necessary for the operation of the digital environment. The second meaning implies data, knowledge, facts and reports.

In both meanings (as a code and as a fact) information, in particular with the development of digital media and information societies, have been given the economic character as well as role in the economy, as a product and a commodity that has its value and it can be sold or bought. As Harviainen and Hamari (Ibid., p. 1119) observe, "information goods are increasingly the products that people pursue as the end products rather using them merely for coordinating other economics activities". Authors indicate that in- formation in the persistent, virtual worlds include different forms and meanings: from those that are necessary for playing and represent basic components of the game, such as "." (Ibid., p. 1120).

Harviainen and parts of storylines, quests and item properties, to systemic (functions of algorithms within the game; the fact that the virtual items consist of information), to meta-game information exchanged during or outside of play by the players Hamari in their work "Seek, share, or withhold: information trading in MMORPGs" analyze social information practices function as means of trade, by using library and information systems theories, management information systems and information economies (Ibid., p. 1120). Having in mind the results of that research, this paper will be focused primarily on aspects of production and the phenomena of both goods and the market, using Marxist thought to analyze the logic of the capitalist economy and theory of media, as well as participatory culture that determines information in the field of digital media and culture.

Proposed subject of the case study - virtual worlds of video games as complex media, technological, social, cultural and economic phenomenon can be analyzed from different methodological perspectives and using different scientific approaches to spheres that these video games include. These games - MMORPG (massive multiplayer online role playing game) owe they specificity to relation between publishers and players, as well as mutual relationship of players in the game world. In these relation- ships, labour, production, ownership and social structure of the real and game worlds constantly overlap.

These phenomena will be observed on several levels: the "outer" level that relates to real or physical world and that pertains to the production and circumstances of playing these games, then from the perspective of relations and conditions in the game world, and finally interrelationships of the game and real world economy that relate to or are dependent on the process of playing will be discussed.

In the beginning it should be noted that playing games, including those that are the subject of this study, is in the realm of play, as a voluntary, predominantly fun, or at least desirable activity (as analyzed from socio-cultural perspectives by Johan Huizinga 1938, 1971 and Roger Caillois, 1958, 1961). Meaning, it is not imposed as 
an obligation, necessity or compulsion, as it is the case with the work as a source of livelihood. Then, the player at their own chooses the conditions of playing (in the extent to which the game allows), aspect of game that they are interested in and she/ he can quit at any point.

Also, the place and role of the economy in the playing experience can be seen from at least two different perspectives. In the case of games that, according to my gaming experience, provide enough content - data and interesting information - in terms of space (world) that can be explored, mini-games (g-mes within games) that can meet the basic ludic and playful needs, or competitions, etc., economic factors have secondary importance and present only side support for other activities. When the game runs out of new and challenging content in the mentioned spheres, game publishers turn focus on collecting goals that draw players' attention to the necessity for possession of certain objects, which then entails purchase and sale, in the game world or in conjunction with the economy of real world (the case of Guild Wars, 2005).

Furthermore, in order to retain players, new game contents are given from time to time. However, these contents do not always have to be new narrative lines, new parts of the virtual world or a new type of PvP. After all, games like Eve Online do not offer the storyline primarily, but are oriented to adventure, which in one way or another, requires acquisition and multiplication of capital and information about the world. The simplest way to retain players is to set new goals, new material objects for a 'wish list' (new weapons, armors or accessories) ownership of which brings social prestige, commodity fetishism in sphere of economy (Marx, Capital I, part I, section 4) or culture (Adorno and Horkheimer, 1944, 2002). Marx's observation from Economic and Philosophic Manuscripts of 1844 is the most illustrative for this phenomena is: in capitalism and with the existence of private property, new needs are created, that cause new dependencies and require new sacrifices for the acquisition of new material elements of consumption or possession as a measure of success. This creates a dependency from the labour that is needed for gaining means for the satisfaction of these needs (1988, p. 49). As Marx argued, with that process the man becomes poorer as a man and in this spirit we can conclude that a game as an element of culture and man's enlightened existence this way loses its crucial determinant.

On the other hand, Edward Castronova (2005, p. 172) believes that the economy is an integral part of the fantasy. He adds: "Nothing makes the world feel more alive than an active market system [...] With very few exceptions, every synthetic world has a set of user institutions, game mechanics, and AI systems that collectively constitute an economy". This statement can be good indicator of conquest of games and entertainment fields by the capitalist economy and market logic.

If we look at issues of production of material goods in the game world, the possession of items as well as invested work, the question is why economies are that de- 
veloped in the game worlds at all, even to the extent that in some cases that is the very goal of the game? Castronova tries to answer that question in chapter 8 ('The Economics Of Fun: Behavioran Design') of his book Synthetic worlds: the business and culture of online games (2005) where he highlights some factors that mark it as genera- tors of fun and happiness or security (consumption and acquisition, fair returns to work and skill, creation of things and of the self, mission and purpose, robust compe- tition under equal opportunity, risks and bargains, and property crime, chaos and history (2005, pp. 177-180). All of these factors can be widely subsumed under obser- vation "Owning things feels good." (2005, p. 179) and attributed to the spirit of the de- veloped capitalist imperative of possession and accumulation of goods. Feeling good and what the players want to achieve in the virtual world is, therefore, oriented to possessions and material goods. The game worlds, from the initial position - character creation and further on, offer (ostensibly, that is, this is before the influence of the real world means) equal opportunities and conditions for all, where (again, ostensibly) everyone can acquire financial resources and enjoy imperative of ownership according to their abilities and skills. Castronova notices "that the economy might usefully be con-sidered as an entertainment product" (2005, p. 176). So economy itself can be considered as product in the chain: game - entertainment economy - product.

Finally in the game worlds, players are (re)presented using the same factor avatar that can be put in correlation with capital analogy and use of information. Castronova differs physical capital (money, armor, items) and non-physical capital (experience points, skill ratings, attribute enhancements), which corresponds to human capital ('education and on-the-job experience that enhance earning power but are intangible and inalienable') and proposes an adapted term - avatar capital. (Castronova, 2005, p. 110). Author underlines parallel: "Possessions are like physical capital, and avatar skills and experience levels are like human capital" (2005, p. 41). Social position of players changes and improves as their avatar progresses, that is, thanks to the in- crease of their avatar's human capital. (2005, p. 72). Also, Harviainen and Hamari point out on Consalvo's concept of gaming capital, "which reflects the skills, status and information needed to become a respected member of a gamerelated subculture" (2015, p. 1124).

In accordance with the initial hypothesis that the use of information in virtual worlds mirrors their application in the real world and that economy of virtual worlds (which operates in accordance with the capitalist logic) represents an interesting study field of these interrelationships, the analysis will be structured so it will consecutively examine observations related to the economy and to the information in certain aspects of these worlds. 


\section{THE OUTER STRUCTURE}

Having in mind proposed approach, it can be started from the outer structure. Under the external structure, the aspects and circumstances of playing and those of the real world related to the game will be analyzed. It is about economic factors of the video game industry itself, which in terms of MMORPGs includes complex crossmedia and transmedia structures as well (economic profit of franchises such as Star Wars or Lord of the Rings), where MMORPG is only one of the video games just another commodity in a complex web of products that provide the same narratives available on various media platforms or narrative extensions scattered in various media (Jenkins, 2006, 2007).

Like all other products, video games are primarily goods exposed to market in a complex chain of labour, means of labour, capital/capitalist and market.

On external level, evident conditions for the sheer approach to the game require possession of certain means for labour or play: first of all, the player should be in a position to invest some time for playing, which can be paralleled to work hours in the real world. This means that they are prepared to set aside time reserved for other activities, in economic terms - that they are financially secured sufficiently so they are able to devote time to fun.

In the terms of Marx's base-superstructure concept $(1859,1973)$, the act of playing is a real world superstructure, it occurs only as a result of above-average solid economic real world base, while the process of playing involves labour, time invest- ment and production of material goods in the game world - elements that are need- ed for the construction of base, work with which one acquires property and social status in the virtual world. So interloping of the perspectives of real and virtual worlds can be seen in the application of these terms.

Also, the player must have a computer that meets the hardware and software requirements necessary for running the game, as well as continuous access to the Internet. Next, he/she must have capital, that is money, to buy the game itself and pay a monthly fee (if applicable to a particular game, from those that are free to play, via those which has to be initially purchased, to those which require monthly subscription) and optionally, to purchase expansion or, from time to time, to buy accessories in order to improve, embellish or jollify gaming experience (purchase character slots, outfits, boosters, minipets, accessories etc.). At this obvious external level, where the real world economy meets the virtual world economy, those areas are interwoven and entwined; certain games have an option to purchase some goods using either money from the real world or that from the game world (the example is the equal possibility of paying off the monthly fee for playing in EVE Online using one of those options). In this case, labour time and efficiency in the virtual world overlap and become comparable with the work or the possession of money in the real world. 
Another practice that radicalizes the use of players' knowledge in the game and use of their playing competence is to engage them in the service of the game world - to provide useful information for other players.

Player's activities and commitment using and sharing information are the main factors of survival of the system such as MMORPG. Uninhabited virtual world, that is, a world without players and therefore without their work, does not attract other players (e.g. state of the Guild Wars after the release of Guild Wars 2) thus making it unsustainable. To make the virtual world to work, constant maintenance and updating data is required. Without players (and their work in providing data in the game and the production of content - information in other media forms (posts on forums, social networks, Wikipedia texts, video materials recorded in the game and uploaded on the YouTube channel, etc.) in relation to the game, the game cannot function.

If we put only investment of time and labour in the initial focus, the nature of the media must also be kept in mind. De Zwart and Humphreys notice about various media spheres: "the boundaries of such environments are becoming increasingly fluid as players extend the game through social media, fan forums, modding, fan fiction, conventions and cosplay." (2014, p. 95). Here, we can recognize the manifestations of participatory culture (Jenkins et al. 2009). Also, John Banks and Sally Humphreys sum up Grossman's observations that the participation in the new media contents, such as book reviews, recording podcasts, creating profiles on social networks, or avatars in multiplayer games are fun, play and relaxing activities, but they are also work and participation in "global intellectual economy" (2008, p. 401), and I can add that it relies completely on transfer of information.

Humphreys $(2005$, p. 47$)$ notices that game is "always unfinished media product, the publishers rely on the players to continue the cycle of development. Thus, we could see the game as a result of a combination of paid and unpaid labour." Author continues with optimistic assessment that "relationship between them is not necessarily exploitative. Players voluntarily participate and are shown to have agency and power within their relationship to the publishers" (2005, p. 49). This point of view can be seen as a contemporary response in the form of calming or mitigating of another, in this context also applicable stand- point of the Frankfurt School, that various forms in which popular culture is ex- pressed act as parts of the culture industry that regulates and directs the audience towards market interests (Adorno and Horkheimer, 1944, 2002).

Also, it does not seem probable that consumers-users-players are so "naïve" and that they "are unknowingly being seduced into activities of work", (in this case obtaining, sharing and producing information), and it is even less likely that "players are in some sense unaware that their participation is a productive practice from which economic value is extracted" (Banks and Humphreys 2008, p. 404). Instead, it is more probable that "hybrid configurations and the entities that emerge, which are an uneasy and at times messy mix of the commercial and non-commercial, mar- 
kets and non-markets, the proprietary and the non-proprietary."(2008, p. 406) This is actually an interdependent mechanism, in which work and production of information in the digital environment are associated with that of the physical world.

The intertwining in the field of ownership and recognition of data can be well seen in the field of legislation and contracts, as an important factor of protection of information, copyright and other rights, as well as various aspects of property: Adam Ruch (2009) notes a difference between the legal treatment of World of Warcraft pre- sented in documents such as the Blizzard's End-User License Agreement (EULA) and the Terms of Use (TOU), and presentation or treatment of game as a space, that is - the world. Ruch analyses complex network of contradictions and implications arising from these determinations, highlighting the problem of ownership of the goods pro- duced, creative capital (that is information) and in the end - the work invested by the players. Here it seems that, given the number of inconsistencies (ownership and copyright over data such as screenshots, machinima products, You Tube walkthroughs, even cosplay costumes etc.) it is still an undefined field. However, corporations and publishers are aware of the importance of players' production, but that apparent discrepancies and tolerance in terms of using copyrighted material and information suggest that the search for solutions how to protect data and at the same time to appropriate and link those products and information that are produced by players based on the game or in the game world - still continues.

This is probably the key factor in determining of the problem of status of in- formation and other labour products in the game world. While the texts concerning the games can belong to their authors/players, almost all other contents belong to the game publishers. As it is already pointed out, the important factor is that the existence of the virtual world and earnings in that sector of gaming industry depend on the players' activity - labour and producing of information in the world game, while all the produced content and meaning are, again, owned by the publisher. This mechanism exploits the fact that playing game often come from making and production of contents and information.

\section{PRODUCTION, LABOUR, MARKET AND INFORMATION IN PREDEFINED GAME WORLD}

Within the game itself predefined elements - data may vary in the terms of the structure of the game (gameplay, storyline, game economy and the way to associate, community structure - guilds/corporations). EVE Online is prominent example of one type of setting and organisation of the gameplay - this game comes from the tradition of science fiction space adventures, located in a dystopian universe in which different power structures (republic, federation, empire) coexist. At the same time, capitalist system whose peculiarities are taken to the extreme is characteristic for the game. EVE leaves almost all the "space" for the content and activities that players produce themselves and allows players to make, build and organise many aspects of 
game content. This can be seen as broad freedom but at the same time, players work, create data and leave all information and products of their work (enriched game world) to the game publisher, who than makes profit from it.

On the other hand, Guild Wars is based on a concept of epic fantasy - basic for RPG (FRP) games. This concept places one into the fantasy setting of Middle Ages in terms of settlement appearance (villages, fortified towns, castles), equipment (armor) and weapons (cold weapons). The player's character may possess private property - a large number of weapons that is used if required, predominantly for the fight. The fight, usually killing of NPC enemies ("mobs") is the basic way to advance through the narrative, and for the acquisition of material goods and therefore in that respect weapons are the means, the tool for work - fight. In the beginning, character is automatically equipped with a single piece of weaponry and an armor, which has to be replaced or enhanced during their progress through the game, in order to be able to cope with all the 'stronger' enemies. This mechanism creates a closed circular (recur- sive) system in which the progress through the game is conditioned by the possession of required tools and means for labour, and its acquisition, again, is conditioned by the amount of effort spent (by killing enemies). The elimination of hostile NPCs is not the only way of gaining information, funds and assets - capital. There are other mech- anisms, systems of quest "rewards" for the deed, service or help given.

As Harviainen and Hamari notice, the quests (I would also add missions, which can be understood as more complex quests) often refer to the search for information, or are available only when the player acquires certain information (2015, p. 1122). In case that one needs further explanations or instructions, e.g. how to acquire information which are integral part of the story and the game world, this metainformation is something that players usually have to seek from other players in the virtual world or on the Internet. Here, information are necessary for the playing itself. From the economic perspective, these are the products that transmit data in the form of blog or forum posts, Wikipedia articles or content on YouTube channels. Labour is essential for the production of these materials, and as any other work it involves investment of time, means for work (computer and specific programs and applications) and the knowledge to use software for the creation of such content.

Trading via game-defined system, communication with NPCs is based on direct supply and demand. Changes in the value of items in the in-game market are determined by different parameters, imposed "from the outside" by the game publishers and developers (e.g. how difficult it is to obtain an object or how rare it is) or from the "inside" - by game communities, as what Castronova notes: "If the player community decides that a certain activity needs to be done with a certain set of avatar roles, and your avatar does not inhabit one of those roles, whatever skills she has may become worthless." (2005, p. 114). 
The price is also affected by materials necessary for the production of armors and weapons which are hard to be gained by playing, so a large number of players is required for their acquisition (which leads to the necessity to associate and for mutual coordination and organization), then many hours playing (working) spent, the skill and experience (capital consisted of the know-how) and, again, adequate tools and means for labour (armor, weapons, 'boosters'). Therefore the activity of well- organized, capable and most skillful that is well informed players - determines the price of certain goods in the game.

Another option is the self-organization in mutual trade in the game. If the players in the game in a chat system arrange a trade, that must be previously enabled by specific software solutions (exchange of goods and money). The game developers therefore may offer certain options as a basis for the development of interaction, including economic ones, among the players, but it is still a controlled process which must maintain the market as a functional unit. As it is above mentioned, killing computergenerated enemies or performing certain tasks (finding, crafting objects, assistance or protection of NPCs during differ- ent tasks) is defined as labour that is done by using different means and knowledge, then the production-labour system (which also brings certain earnings) is necessary for progress through the storyline. This way, enjoying the narrative, even the ability to access further course of the story and certain game areas is conditioned not only by the quantity, but also the speed and quality of performed work.

In this way the progression through the narrative or gaining access to certain parts of the game can be seen as a reward or pay for the work.

What separates this mechanism from a single player game is the division of labour - the players most often perform tasks in groups, in which the characters are differentiated according to the specific functions within the group. This division of labour (Marx, Capital, Volume I, part III, Chapter X, Section 4) is a predefined by a set of functions and skills that each of the characters have, as well as individual capabilities of players. Also, in games where there are possibilities for such activities, the players pay to each other the agreed sum of in-game money or goods to help them or cross from one point to another ('taxing') or play certain parts that require more time to play. This exchange indicates a specialization in a particular field of play, the division of labour. The information can also be the reimbursement for help, or they are payment for such assistance e.g. how can some other task be done, or where to gain more material goods in the game world - data represents the means of exchange that can be used as barter, it is the subject of negotiation and agreement for determination of value exchange (Harviainen and Hamari, 2015, pp. 1129-1130).

Also, sharing the information without reimbursement can be considered as a transaction. This can be considered a way of showing "good will", a way to acquire the reputation in the gaming community or social capital (Bourdieu, 1984 in Harviainen and Hamari, 2015, p. 1124). These tips can be shared in the game or outside 
it, on forums, blogs and YouTube channels. Harviainen and Hamari also point out to the essential interdependence of MMORPGs as games and the social structures in them, and of those that arise from them (2015, p. 1123). To participate in the fan clubs, gaming communities, conventions, cosplays, activity on social networks, it is necessary to possess a wide range of information about the virtual world. These practices Harviainen and Hamari defined as "interconnected participant practices"; also "players who have access to more information have access to potentially more game content, and as a result the ability to share that access with others" (2015, p. 1123).

Other way to progress through the game in terms of character leveling as well as its "ability" for production is training in crafts - cooking, forging, tinkering, jewel crafting. This type of training and knowledge falls under the "grind" phenomenon because it is "just a matter of clicking on items and dragging them from one container to another in a particular formula over and over again" (Humphreys, 2005, p. $40)$.

Practice of grinding together with focusing on a single aspect of the game and repetitively performing the same or similar activities in order to obtain material goods (farming), which is not directed toward the progress through the narrative or an exploration of the virtual world, can be compared to the specialization of workers in certain narrow aspects of production. This way, the player is solely focused on a sim- ple reproduction of capital using mechanical repetition.

Those kinds of specialization fit with one of the forms of Marx's concept of alienation - alienation from the process of production: "With this division of labor on the one hand and the accumulation of capitals on the other, the worker becomes ever more exclusively dependent on labor, and on a particular, very one-sided, machine-like labor. Just as he is thus depressed spiritually and physically to the condition of a machine (...)." (Marx 1988, pp. 22-23).

From constant labour and the production of goods, which the player acquires in the process of farming and from social relations in the game worlds, aspect of alienation are emerging. A player can play only if he/she earns for it, if he/she equips his/ her avatar in a satisfactory way, has enough knowledge and if other players assess that his/her equipment is good enough for the play in the group (especially noticeable in World of Warcraft). Also, in order to participate in certain activities collectively, players have to acquire information and knowledge of know-how through the learning process, by searching and collecting information on the Internet (Harviainen and Hamari, 2015, p. 1125).

Alienation thus occurs in various aspects: the alienation of the products of labour, from the sole production activity, as well as suffering and self-alienation. Finally, according to Marx, alienation of man from other man occurs as a result of alienation from production (Marx, 1988, p. 32). These practices recall the Adorno's view that the entertainment in the conditions of capitalism is labour extension and 
that, thanks to the mechanical reproduction at all levels, entertainment is a copy of the labour process and becomes an automated set of standardized activities (2002, p. 109).

On the other hand, the main specificity of information (and knowledge, I will add) as a commodity - unlike other goods - is that anyone can share or sell information, and not lose it by doing so, meaning, to still own it (Lehdonvirta, 2009, Harviainen and Hamari, 2015, p. 1124). Therefore, we can first and foremost speak about sharing rather than selling of knowledge and data. However, indirectly, this affects the virtual world economy, or values of different processes in the game world, espe- cially collecting material goods or means for character's advancement (farming and grinding) - that is, data about best location to perform those actions on the most efficient ways, or the ways in which it can be done most effectively (e.g. which skills and equipment should be used). But if many players know the way and location for the acquisition of goods or the way to optimize the speed of labour process, meaning, quicker and easier acquisition (whether it is about specific materials or other items, or points that determine the knowledge capital and reputation, or procedures required for the acquisition of a certain title) that leads to overproduction, which devalues the product, or goods. That way, the flow of information influences the market of material goods. The same logic can be applied to withholding of information - thus giving exclusivity to specific goods or characteristics, because they remain rare and difficult for acquisition. Also, preserving the information for oneself creates "artificial scarcity, information becomes capital" (Harviainen and Hamari, 2015, p. 1123).

\section{MEETING OF ECONOMIES AND INFORMATION MANAGEMENT OF REAL AND VIRTUAL WORLDS}

Even though this topic might be a logical continuation of the phenomena described in the section of this paper devoted to "external" factors, where I already argued about permeation and collision of the real and virtual worlds" economies and information management, it was necessary first to examine characteristics of the ingame economy and the role and place of information in order to find some conclusions about the encounter of production of virtual goods and its" relation with information and economies and information system of the real world. Also, many phenomena that indicate the junction of these fields have already been indicated in previous sections.

One of the crucial issues in this field is illegal (from both legal and game rules perspective) trade among the players, the exchange of goods and information - product of skills and time spent working in game for real money. Such activities enable the possibility to compere the knowledge, labour and market values in the real and virtu- al world and open field for mixing and interfering of game rules and real world laws, in the economy, information management and legal fields (that can be set as 
separated topic of analysis). Developers and publishers prohibit such trade - keeping the integrity of the game as the game rather than the agency of earning money and economy factor, but also, as the owners of the software, data and graphical materials and scenarios, they reserve the sole right to sell product and earn money on the content of the virtual world, in other words to use game content as capital.

Castronova puts into perspective of the capitalist logic of the labour, goods and money market above-mentioned phenomena - selling items collected in the pro- cess of farming. Author examines "the possibility that unskilled labor markets may affect the value of playing" (2005, p. 150) and represents the capitalist point of view on recursive relation between in-game and real world factors: labour and value of money and playing. "(...) unskilled labor has been hired to do nothing but mindlessly farm the world for gold pieces, say, by killing monsters and looting their treasures of coins over and over and over. The gold is then sold on eBay. In worlds where this practice has developed, the value of gold pieces against the dollar rapidly drops and, therefore, the value of assets obtained by everyone in the game drops as well' (Castronova, 2005, p. 150).

Also, Harviainen and Hamari observe that "with the RMT, players purchase information services that enable them to play games less." (2015, p. 1127). However, even though this may seem paradoxical, it is not induced by desire to generally reduce the time and quality of play. On the contrary, here we can notice the opposite process: reduction of needed time, or avoiding to deal with boring and repetitive activities of alienated labor, thus leaving more time for desirable and fun activities what the game is actually all about.

In addition, information are also part of the capital and can be treated as a commodity to be traded on the market: "ranging from game-world internal parts of storylines, quests and item properties, to systemic [...] to meta-game information exchanged during or outside of play by the players" (Harviainen and Hamari, 2015, p. 1120). Some tasks require learning and training and that requires time and resources (either the value of the game, either real money trade - RMT) and Harviainen and Hamari conclude "Because of the artificial scarcity, information becomes capital, as well as something that can be given, sold and bartered" (Ibid., 2015, p. 1123).

At the same time, players in the real market sell, buy and transfer ownership of game accounts containing developed characters, high-leveled and fully equipped. In economic terms and in comparison of playing and/or entertainment with private property, this form can be characterized as a pure necessity for owning, without interest in playing, acquiring knowledge and other information related to the virtual world, amusement found in the progress through the game, solving problems and overcoming obstacles and without enjoying the storyline during the character advancement. Counterargument indicates that only fully-developed and well-equiped characters can participate in PvPs or certain end-game contents (e.g. dungeons), which is the motive for such a purchase by players who are not interested or do not 
have time for the other aforementioned aspects of gameplay, but specifically wish to partic- ipate in certain game aspects. Also, the motive can be position and reputation in the community, almost class recognition arising from the ownership, a sign of possessing in-game capital or posession of information, skills and experience for acquisition of goods: in that case avatar and equipment are goods into which time and effort have been invested (Humphreys, 2005), so, indirectly, the appearance and characteristics of avatars indicate information and knowledge capital that the player possess (Harviainen and Hamari, 2015, p. 1127). Also, by using microtransactions (paying for content of the virtual worlds with real money) the players buy information and increase social capital: "This includes the ability to dig up and potentially share information on areas of the systems to which not everyone has access without the RMT. Players use such information sharing, especially if they can do it faster or better than others, as a source of social capital" (2015, p. 1127).

\section{CONCLUSION}

Whether due to the restrictions of the range of predefined narrative material in games (in terms of their lack) or due to the planned lack of defined storyline, the players in virtual worlds are oriented towards the acquisition of material gain, getting rich in terms of assets, money and means and resources for the work, in short, they turn towards economic copying of the world outside the game. Information needed for these activities fit into the production model (in terms of production of meaning and knowledge) and the exchange (as shown, more in the form of barter rather than the trade). Due to the complexity of virtual worlds and their various use, acquisition, flow and exchange of information are absolutely necessary and without them it is often impossible to participate in such environment. However, they are indicated as necessity for players to use, to be entitled to be able to participate at all.

Video game industry flourished at the time of expansion and general domi- nance of capitalism in its extreme forms; its very distinctive developed forms MMORPGs reflect the state of the world and their own economic and market oriented nature onto their contents - the virtual worlds. From the given analysis, it can be concluded that this mirroring of the capitalist logic is also noticeable in the case of infor-mation managing: at the same time they are product/goods as well as the means used for transaction/exchange, and as such have their own value. On the other hand, partic- ipatory culture has enabled a freer flow of information in which funds for the labour, knowledge, time and effort are invested in the placement. In addition, sharing data and knowledge this way brings certain benefits, reputation in the community, or self- esteem, and can be reduced to the logic of capitalist social capital and capital of knowledge.

A special category where a strong tendency to treat information as part of capitalist logic is noticeable (and therefore an element of the production process and the creation of capital) in the process of alienation through the playing MMORPGs are 
labour of the players (used by the game publishers) and setting up new goals in the virtual world with promise of equal opportunities and conditions as well as rewards and salaries in accordance with the personal abilities and invested labour. They require more time spent in the game and often endless performance of simple repetitive activities of farming, all of which leading to alienation. Alienation can be seen at all levels in the virtual world, and as previously shown, also as alienation of the process of labour, its products, but also on the humanistic level, alienation from themselves and from others. In these processes, information are used in order to optimize the process of repetitive activities and to reduce the time needed for the acquisition of certain goods, but by gaining of these knowledge or general accessibility and sharing of these information, the goods are made to be more accessible and thus their value decreases. This leads to reciprocally dependent mechanism of alienation of labour related to the production and possession of goods and gaining and sharing of the knowledge.

Assessment of the impact of virtual environment on the physical world, individuals and society, or drawing conclusions about the state of society based on video games is both methodologically and theoretically delicate area, and a field to which this paper does not have any pretensions. However, some implications and conclusions in this area are emerging. It can be concluded that treatment of information as necessity, and therefore also the prerogative on one, and as goods and production value on the other hand, fits with general tendencies of practice of mirroring the occurrences of the real and virtual world in which gaining and sharing of information through labour and market logic is no different than the production and managing of material goods. Whether it is about information or other goods, virtual worlds copy the oppressive system of alienated labour and the anxiety of long working hours that increase the costs and bring little joy and satisfaction in something that still contains word "game" in its title. The causes of such system must be looked for in the "real" world and its economic, social, cultural or even the educational system and the way it shaped an individual as well as the group alienation from, speaking freely, the basic postulates of human existence.

\section{REFERENCES}

Adorno, T., Horkheimer, M. (2002), Dialectic of Enlightenment; Philosophical Fragments, (ed. Gunzelin Schmid Noerr), Stanford University Press, Stanford.

Banks, J., Humphreys, S. (2008), "The Labour of User Co-Creators Emergent Social

Network Markets?", Convergence: The International Journal of Research into

New Media Technologies, Sage Publications, Vol 14, No. 4, pp. 401-418.

Caillois, R. (1961), Man, Play, and Games, University of Illinois Press.

Castronova, E. (2005), Synthetic Worlds: The Business and Culture of Online Games, University Of Chicago Press, Chicago and London. 
De Zwart, M., Humphreys, S. (2014), 'The Lawless Frontier of Deep Space Code as Law in EVE Online', Cultural Studies Review, Vol. 20, No. 1, pp. 77-99.

De Zwart, M. (2009), "Piracy vs. Control: Models of Virtual World Governance and Their Impact on Player and User Experience", Journal of Virtual Worlds Research, Vol. 2, No. 3.

Gere, C. (2008), Digital Culture, Reaktion Books Ltd., London.

Harviainen, J. T., Hamari, J. (2015), "Seek, share, or withhold: information trading in MMORPGs", Journal of Documentation, Vol. 71 Iss. 6, pp. 1119-1134,

Huizinga, J. (1971), Homo Ludens, Beacon Press.

Humphreys, S. (2005), "Productive Players: Online Computer Games Challenge to Conventional Media Forms", Communication and Critical/Cultural Studies, Vol. 2, No. 1, pp. 37-51,

Jenkins, H., Puroshotma, R., Clinton, K., Weigel, M., Robison, A. J. (2009), Confronting the Challenges of Participatory Culture: Media Education for the 21 st Century, Mambridge, MIT Press, London.

Jenkins, H. (2006), Convergence culture where old and new media collide, University Press, New York.

Jenkins, H. (2007), 'Transmedia Storytelling 101' http://www.henryjenkins.org/ 2007/03/transmedia_storytelling_101.html.

Marx, K., Engels, F. (1988), Economic and Philosophic Manuscripts of 1844 and the Communist Manifesto, Prometheus Books, New York.

Marx, K. (1996), Capital, Vol. I, Marx/Engels Collected Works, Vol. 35, Lawrence\&Wishart, London.

Ruch, A. (2009), 'World of Warcraft: Service or Space?' Game Studies, Vol. 9, issue 2, November, http://gamestudies.org/0902/articles/ruch. 